\title{
Rethinking Peer Review: Expanding the Boundaries for Community-Engaged Scholarship
}

\author{
Sherril B. Gelmon
}

Cathy M. Jordan

Sarena D. Sheifer

Recommended Citation:

Gelmon, S. B., Jordan, C. M., \& Seifer, S. D. (2013). Rethinking Peer Review: Expanding the Boundaries for Community-Engaged Scholarship. International Journal of Research on Service-Learning and Community Engagement, 1(1), 1-10. 


\title{
Rethinking Peer Review: Expanding the Boundaries for Community-Engaged Scholarship
}

\author{
Sherril B. Gelmon \\ Portland State University \\ Cathy M. Jordan \\ University of Minnesota Extension \\ Sarena D. Seifer \\ Community-Campus Partnerships for Health
}

\begin{abstract}
Peer review in the academic arena is the evaluation of a scholar or a scholarly work by peerstypically, qualified members of the scholar's discipline or profession with similar or greater competence, expertise, or rank. Peer review serves as a mechanism of self-regulation within a field or an institution in order to assure quality and may be applied to a product of scholarship, to scholars and their bodies of work, or to programs and organizations. Special considerations arise when peer review is undertaken in the context of community-engaged scholarship (CES), since CES generally involves partners outside the academy, and the typical concerns of peer review (such as rigorous methods, participant risks and benefits, and significance of findings for the field) are complemented by equivalent and sometimes greater concerns for the quality of the engagement process, communitylevel ethical considerations, and benefit to the community. This article, authored by some of the founding members of the Working Group on Rethinking Peer Review, explores these issues and invites readers to contribute to this discussion by considering questions about the appropriateness of conventional peer review mechanisms and who should be considered "peers" in reviewing products of CES and the work of community-engaged scholars. The Working Group hopes others will initiate discussions within their own institutions, professional associations, journals, and other settings to debate the notion of peer review and determine if expanded concepts are feasible. Through these various activities, the authors hope to begin seeing changes in the peer review process that embrace community expertise and enhance the quality and impact of CES.
\end{abstract}

Keywords: peer review; community-engaged scholarship

Peer review in the academic arena is the evaluation of a scholar or a scholarly work by peerstypically, qualified members of the scholar's discipline or profession with similar or greater competence, expertise, or rank. It is intended to be a mechanism of self-regulation within a field or an institution in order to assure that standards of quality are met, demonstrate credibility, and encourage improvement. Peer review may be applied to a product of scholarship (e.g., manuscript, book, creative work, or performance), other scholarly activities such as grant proposals, conference abstracts, and ethics review submissions, and scholars and their bodies of work (e.g., for awards, hiring, annual review, and promotion and tenure). Peer review may also apply to programs and organizations (e.g., accreditation).

Special considerations arise when peer review is undertaken in the context of communityengaged scholarship (CES), since CES generally involves partners outside the academy, but these partners may not be traditional participants in the peer review process (Calleson, Jordan, \& Seifer, 2005). CES is conducted by faculty who apply their expertise to real-world problems through collaboration with peers in other sectors and also bring their knowledge and wisdom to the table in 
order to generate, disseminate, and apply new knowledge (Gelmon, Jordan, \& Seifer, 2013; Seifer, Hawkins, Daly, \& Fletcher, 2011). In CES, the typical concerns of peer review-focused on rigorous methods, participant risks and benefits and the significance of findings for the field-are complemented by equivalent and sometimes greater concerns for the quality of the engagement process, community-level ethical considerations, and benefit to the community (Jordan, Wong, \& Jungnickel, 2009). How these additional considerations are best addressed raises questions about the appropriateness of conventional peer review mechanisms and who should be considered "peers" in reviewing products of CES and the work of community-engaged scholars.

In 2012, after several years of being confronted with challenges raised by CES to traditional notions of peer review, a small group (the authors and other colleagues) launched the Working Group on Rethinking Peer Review to rethink the concept of peer review. Through two interactive sessions at the 2012 International Association of Research on Service-Learning and Community Engagement (IARSLCE) Conference and the 2013 Association of American Colleges and Universities (AAC\&U) Conference, individuals interested in this topic participated in a structured process to generate ideas about expanding the boundaries of peer review while retaining its fundamental principles. The collective expertise of the participants reflected roles as higher education faculty, administrators, and funders; membership on the editorial boards of multiple journals; leadership and participation in CES4Health.info; participation in tenure and promotion review committees; and personal experiences as providers and recipients of external peer review. A small number of community members involved in community-academic partnerships participated in these sessions, as well as some graduate students. The findings reported here therefore reflect primarily an academic orientation; a more complete discussion of community member perspectives on peer review is beyond the scope of this paper (but may be found in, for example, Freeman, Gust, \& Aloshen, 2009).

This article provides an overview of mechanisms and characteristics of peer review, the challenges that conventional peer review practices pose to the community-engaged scholar, and innovations in peer review processes. It also provides a thematic report of the conversations at IARSLCE and AAC\&U. Through this article, we hope to stimulate a broader dialogue about rethinking the concept, traditions, and practices of peer review in the academy that could aid in identifying opportunities for further building an agenda for future research, practice, and policy.

\section{What Do We Know About Peer Review?}

Peer review in the academic arena is intended to be a process that is fair, equitable, timely, and free of bias, and that encourages rigorous scholarship (National Institutes of Health, n.d.). The tradition of peer review goes back to as early as the 1700s and the Royal Society of London's review of scientific work (Kronick, 1990), yet the process did not become institutionalized until the middle of the $20^{\text {th }}$ century as a means to manage reviews of increasing numbers of articles submitted to scholarly journals and "to meet the demands for expert authority and objectivity in an increasingly specialized world" (Burnham, 1990, p. 1324). Peer review helps to maintain and enhance quality both directly, by detecting weaknesses and errors in specific works, and indirectly, by providing a basis for making decisions about rewards and "punishment" that can provide a powerful incentive to achieve excellence.

A "peer" is defined as "a person who is equal to another in abilities, qualifications, . . . and social status" (Day, 2011), but in the context of peer review it often refers to people in the same discipline or profession who are of the same or higher ranking. In the academic context, peers are usually considered to be from the academy. Peer review utilizes the independence and, in some cases, the anonymity of the reviewers in order to discourage favoritism and obtain an unbiased evaluation. Typically, the reviewers are not selected from among the close colleagues, relatives, or friends of the 
creator or performer of the work, and potential reviewers are required to disclose any conflicts of interest.

Peer review takes place in multiple contexts with different kinds of peers providing reviews with variable scrutiny resulting in different levels of credibility and perceived value. Higher levels of scrutiny tend to be applied when the consequences of making an error in the review process are higher. For example, judging a medical intervention to be safe when it is not, judging an expensive research project to be worth the investment when it is not, or deciding to tenure a professor who later becomes unproductive represent review errors that would have significant monetary or human costs. In contrast, the consequences of bestowing an honor on one person when another is more qualified or accepting a proposal to present preliminary findings at a poster session that are later disproven are relatively inconsequential. We tend to believe in the quality of the review-and therefore place more value on it-when the level of scrutiny has been high. Examples of these contexts and some typical characteristics are provided in Table 1; however, the characteristics described in the table are not universal. For instance, there is variable scrutiny within each category. Some academic journals provide more rigorous reviews than others. Randomized clinical trials of invasive procedures receive a more detailed and critical review by funding agencies and/or research ethics boards than, for example, survey research would in the same reviews. The nomination and review process for a very prestigious international award is, as another example, generally more demanding than for an institutional award.

While there are many perspectives on peer review that could be considered, we focus on peer review of products of scholarship and of scholars (and their related bodies of work). Peer review is a long-standing tradition and cornerstone of the academic culture and is ideally designed to embody respect, provide constructive critique, and serve as a developmental agenda for helping the scholar and improving the presentation of the work (Burnham, 1990). Peer review mechanisms were developed to serve what we now consider to be "conventional" products of scholarship and scholar roles. Traditional peer review does not work as well in the context of CES because of nontraditional approaches to scholarship used in CES; different partners, including those outside the academy, and the sharing of power, responsibilities, and credit with those partners; new notions of who peers can be and who has expertise; and what products may be produced for dissemination to diverse audiences.

\section{The Challenges of Peer Review in the Context of CES}

While there are many positive aspects to peer review, scholars often find the process slow and cumbersome and may feel that the feedback provided is not constructive. Peer review of CES raises additional concerns and questions. Community-engaged scholars may view peer review as receptive only to the established methods and approaches used by their discipline or profession, rather than accommodating community-based, participatory endeavors and products that may not fit the tradition of authoring books or publishing in peer-reviewed journals. Traditional peer-reviewed journals may not have the capacity of reviewer expertise to review CES. Further, such journals are not appropriate venues for peer review of innovative products of CES that do not take the form of journal articles; in fact, there are very few mechanisms for the peer review of such innovative products of CES other than CES4Health.info (Jordan, Gelmon, Ryan, \& Seifer, 2012).

Rigor and significance, or impact, are foundational criteria within peer review of both scholarly products and scholars themselves. However, these concepts are usually defined narrowly. Rigor in research, for example, relates to the appropriate application of the principles of the scientific method. Yet, in high-quality CES, rigor might also mean the appropriate application of principles of partnership $(\mathrm{CCPH}, 2006)$ and the use of community engagement to enhance the quality of the study (Calleson, Kauper-Brown, \& Seifer, 2005; Jordan, Wong, \& Jungnickel, 2009). In peer review, the impact of the work is usually defined by the significance of the contribution the work makes to the 


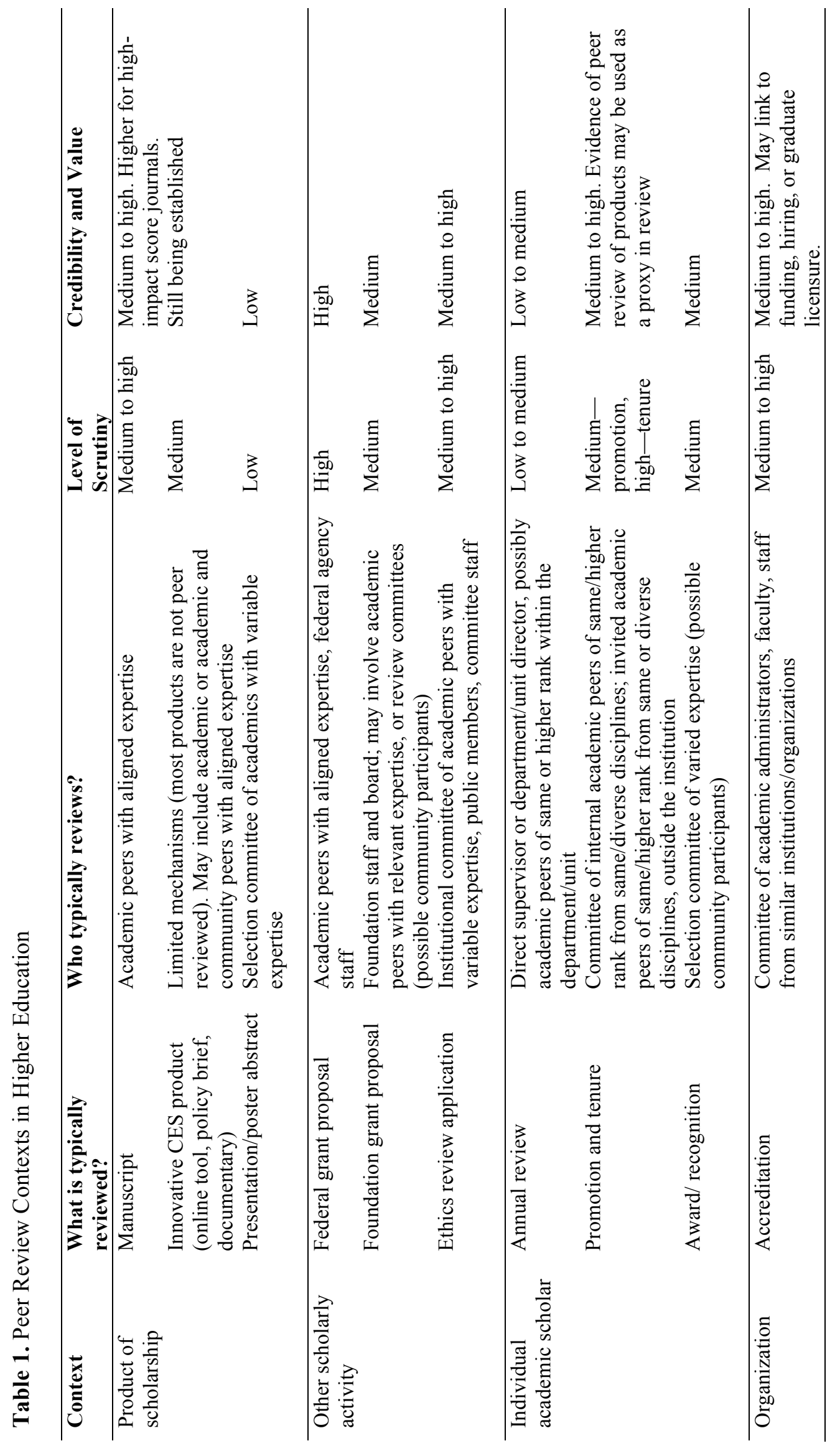


academic discipline and its literature. Often, the journal impact score is used as a measure of this impact-yet real-world impact is not the same as the impact factor, and scholars and administrators need to understand and clarify the distinction between the two (Wineburg, 2013) and appreciate the importance of the latter in the work of community-engaged scholars. A narrow perspective of impact may "reinforce a selfish choice of personal research productivity over broader scholar impact" (Northcraft \& Tenbrunsel, 2012, p. 305) - a notion that runs counter to the overarching sentiment of involvement with a community in a mutually beneficial partnership that is generally associated with CES (Community-Campus Partnerships for Health, 2005).

In CES, planning for and assuring community benefit holds equal or greater weight with disciplinary impact. The community-engaged scholar who is able to balance community need, community benefit, methodological rigor, and academic contribution is indeed accomplished. The practice in peer review of utilizing academic peers as reviewers is grounded in a belief about who is qualified to judge the merits of a scholar and his or her scholarly products. In CES, dimensions such as community impact, quality of the community engagement process, and the successful balance of community and academic priorities require the judgment of community peers who are uniquely qualified to know what rigor and impact look like at the community level.

A growing number of national organizations (including Community-Campus Partnerships for Health, Imagining America, and the American Sociology Association, to name a few) are embedding these issues in the larger discussion of CES and calling for reconsideration of the practices of traditional peer review. These include suggesting a reconceptualization of the review criteria as well as considering who serves as reviewers. The Working Group on Rethinking Peer Review seeks to consider all of these aspects of this topic.

\section{New Modes of Peer Review}

Work in recent years such as the 2009 launch of CES4Health.info, an online mechanism for peerreviewed publication and dissemination of diverse products of CES under the auspices of Community-Campus Partnerships for Health, has stimulated discussions about ways to broaden the notion of peer review (Jordan, Gelmon, Ryan, \& Seifer, 2012; Jordan, Seifer, Sandman, \& Gelmon, 2009). This might include the venue for review, the venue for publication, and the expertise of the reviewers. Whenever this topic is raised, there is much excitement and receptivity to the idea, along with simultaneous fear about whether products going through such review will still count toward faculty hiring, performance reviews, promotion, and/or tenure. While some universities in the United States and Canada have adopted a broader notion of scholarship in their tenure and promotion review criteria, even at those institutions there is still some skepticism about nontraditional peer review mechanisms and recognition of nontraditional scholarly products (Gelmon, Jordan, \& Seifer, 2013; Wenger, Hawkins, \& Seifer, 2012).

Community partners also have questions about the definition, theory, and practice of peer review and suggest that they should be considered as peers in the peer review process since they have relevant expertise, and promotion and tenure of their academic partners matters to them and the work of their organizations (Freeman et al., 2009). Many academics and organizations such as Community-Campus Partnerships for Health agree with this position. Community-based experts serve as peer reviewers for CES4Health.info and for Progress in Community Health Partnerships, a journal of the Johns Hopkins University Press. Submissions to Community-Campus Partnerships for Health's conferences are reviewed by a selection committee of academic and community members. Some universities are going significantly beyond the minimum requirements for involving nonacademic peers in ethics review processes (e.g., the University of Toronto HIV Research Ethics Board; see http://www.ohpe.ca/node/13590) or inviting community reviewers as part of the promotion and tenure process (e.g., Morgridge College of Education at the University of Denver; see 
http://depts.washington.edu/ccph/pdf_files/APT_policy_Final_May_18_2009.pdf). Some funding agencies value community as well as academic reviewers (Kotchen \& Spellecy, 2012).

Discussions of current practice and questions for future directions can inform a strategy to encourage more innovative thinking about peer review. At the 2012 IARSLCE and 2013 AAC\&U conferences, we sought to supplement this knowledge through dialogue with conference participants.

\section{Rethinking Peer Review: A Thematic Report of Conference Discussions}

Through a generative World Cafe dialogue at the 2012 IARSLCE Conference, approximately 40 participants, including faculty, graduate students, community partners, and higher education association representatives, identified key ways that the current system of peer review both challenges and supports the aim of producing more high-quality CES (Schieffer, Isaacs, \& Gyllenpalm, 2004). A similar discussion at the January 2013 AAC\&U Annual Meeting offered additional insights. Four key themes emerged from the session discussions and subsequent thematic analysis of the notes:

- The notion of accountability may need to be broadened given a commitment to helping to address community questions with scholarly approaches.

- The scope of who is considered a peer needs to be reexamined in light of communityacademy partnerships and a wider notion of accountability and expertise.

- Development of scholars and attention to their learning and professional development need to be reemphasized in the processes of peer review.

- Further study should focus on understanding the relationships between various systems of peer review and particular CES outcomes.

\section{Broadening the Notion of Accountability and Expertise}

Accountability and expertise are at the core of the intent of peer review processes, with the assumption that accountability and responsibility in the process of conducting scholarly work contribute to its quality and that expertise is necessary both to conduct and to evaluate the work. In considering possible publication and funding decisions, as well as in making tenure and promotion decisions, a system is needed that assures that work is of high quality, integrity, and relevance. In particular, funding by public agencies requires that scholars answer fully to their peers and to the wider society. Three questions emerge when considering the notion of accountability in the context of expertise. First, is the current system effective in holding scholars (who have expertise) accountable? Second, how does the notion of accountability shift in CES? Third, who truly has the expertise for the process of review?

Participants in the dialogues noted that peer review processes often take into account factors such as institutional affiliation and reputation, as well as evidence of accomplishment. These criteria do not assure that the most worthwhile scholarship gets published or that the most deserving individuals advance in their institutions. Furthermore, in some instances, an entrenched standard for accountability has led to a narrowing of the scope of scholarship as faculty climb the promotion ladder. There is a false sense that current criteria are neutral measures of quality, rather than contextually specific value judgments. Many institutions maintain a high degree of control over what kind of teaching and research gets done - not by asserting a stance but by standing behind a "right" way that they have defined. This status quo is maintained by an insistence that junior faculty surmount the same hurdles as their senior colleagues have done previously. Accountability, then, can be conceived of as a judgment on how well the discipline or institution is served, rather than how well the students or community are served. This runs counter to the major concepts of community responsiveness and reciprocity underlying CES. 
CES raises further questions about accountability. Since CES quality may be defined more in terms of community relevance, inclusivity, applicability, and sustainability, questions of accountability should be determined in part by peers from the community. Yet, session participants pointed to the difficulty of integrating community partners into the system of peer review as it currently exists. Proposals to address this included alternative structures, such as the possibility of earning a formally recognized "seal of approval" from a community organization or communitybased review process, and then bringing this to the academy for recognition (Albert Einstein College of Medicine, 2012). Another approach would involve training community partners to serve on academic review committees. If academic departments are willing to shift some of their accountability checks to community-based individuals, clear guidelines and explicit boundaries about how quality work is defined and compensated will help to maintain and ensure legitimacy.

\section{Reexamining Who the Peers Are}

Given this shifting notion of accountability, a second theme emerged centering on the question of who is asked to hold scholars accountable. One's conception of peers both reflects and determines who scholarship serves and who benefits from it. In the sessions, participants suggested ways of shifting this definition to more closely match the goal of accountability to the wider community. Typically, in the academy, peers include fellow scholars within and outside a scholar's field, administrators, consultants, and graduate students. Nonacademic peers may include granting agency program officers, government officials, and community, nonprofit, and business leaders. Participants noted the importance of including more peers whose qualifications are chiefly in their professional, rather than educational, experience. Emergence as a leader in the relevant topical field is a particularly valid criterion for reviewing CES. Once again, the issue arises of how to include these kinds of qualified individuals in the peer review process. Since many peers are socialized rather than explicitly trained in the norms of peer review, an uninitiated peer will have difficulty participating. This suggests the need for more formal training for academic and community peer reviewers alike.

\section{Refocusing on Learning and Development}

The third theme is the importance of feedback and reflection from multiple perspectives as key aims of peer review. While quality control is essential, conference participants pointed to the potential for scholars to learn from their peers-including those in the community-and to sharpen their scholarship through dialogue, particularly when submitting journal articles for publication. Thus, another way of looking at the qualifications of peer reviewers is in terms of their ability to identify and articulate areas for improvement, helping the scholar in his or her developmental process. For community-engaged scholars, these areas would include improvement in core competencies for CES (Blanchard et al., 2009). Part of this skill is critical self-awareness of one's perspectives and biases, which participants discussed as key qualifiers of a good peer reviewer. In some sense, proprietary and individualistic attitudes about knowledge in the Western educational tradition may not complement the aims of impartial examination of others' work and subsequent coaching to expand and enhance perspectives. To be a good reviewer requires putting aside one's own biases in order to offer an objective assessment to a peer.

\section{How Peer Review Might Be Studied and Revised}

Finally, participants raised questions for research, namely around measuring current models of peer review and studying new alternatives. Participants asked how to measure the outcomes of alternative tenure strategies, determine which are unsuccessful and why, and profile the outcomes and 
8 | International Journal of Research on Service-Learning and Community Engagement

competencies involved in successful community partnerships. They called for a survey of the current landscape of peer review procedures that are central to the academy and relevant to CES, as well as efforts to facilitate sharing of innovative practices in promotion and tenure and to develop understanding of why institutions have made particular choices about the boundaries of peer review. The impact of CES and how to measure it is at the center of these inquiries. The work of organizations such as Imagining America, the American Sociology Association, CommunityCampus Partnerships for Health, the New England Resource Center for Higher Education, and AAC\&U could be explored and reported in a single place, as these organizations are working on one or more aspects of peer review. At the same time, some participants were reluctant to raise questions about the scope of peer review in their institutions, lest they damage their own professional relationships and future personnel reviews.

Participants also raised several critical questions revolving around the possibility of a new paradigm in peer review. The inclusion of more reviewers from the community would require managing not only context-sharing but also logistics and compensation. To facilitate this, participants asked how a metric for nonacademic reviewers might be prepared, and whether a profile of competencies for the review process could be created; this would, by necessity, apply to all reviewers, not just nonacademic reviewers, thus enhancing the expectations of all reviewers. Additional questions for further study addressed the implications of trends such as self-publication, mass dissemination, the Internet, social media, and crowd-sourcing.

\section{Moving Forward}

With the launch of the International Journal of Research on Service-Learning and Community Engagement (IJRSLCE), which is reviewed by academic peers and expected to be "rigorous" (IJRSLCE, 2013), IARSCLE has an opportunity to take a leadership role in expanding the dialogue about peer review and actively modeling strategies to better review and respond to products of CES. Such actions would also help the professional development of graduate students, junior faculty, and community-based scholars who seek to conduct relevant and meaningful CES that will be accepted, recognized, and rewarded by both the academy and community stakeholders. As an organization, IARSLCE can actively promote and enhance CES from a scholarly perspective by adopting and helping to promote a broader definition of peer review and following practices that include reviewers from outside the academy for both abstracts submitted for the IARSLCE research conference and manuscripts submitted to IJRSLCE.

Discussions about peer review should include addressing questions raised through our deliberations to date, including:

- What is the purpose and value of peer review? Does it matter if the focus is review of people or review of products?

- Who are the "real" peers?

- Who selects the peers?

- What makes the peer qualified to review?

- What assurances are there that the peer, whether an academic or community reviewer, has the relevant expertise to conduct the review of a person, product, application, etc.?

- What training do/should peer reviewers get?

- Should all peers review the same things using the same criteria?

- What resources are there to help individuals prepare to be "subjects" of peer review (personally or their products)?

We intend to continue this dialogue via the Working Group on Rethinking Peer Review website (http://www.rethinkingpeerreview.org) and invite readers to contribute to this discussion by posting 
comments, participating in the development of a working paper, and suggesting and/or initiating research projects related to peer review. They also encourage readers to consider initiating discussions within their own institutions, professional associations, journals, and other mechanisms to debate the notion of peer review and determine if expanded concepts are feasible. Through these various activities, we hope to begin seeing changes in the peer review process that embrace community expertise and enhance the quality and impact of CES.

\section{Acknowledgements}

The authors gratefully acknowledge the contributions of Susan Gust, Cathy Burack, and Elaine Ward for their involvement in planning the initial work of the Working Group on Rethinking Peer Review. In addition, Julia Rodemeier, Becky McNamara, and Kevin Kecskes provided valuable assistance as notetakers at the IARSLCE Conference session. Susan Agre-Kippenhan, Judith Ramaley, and KerryAnn O'Meara offered their personal and disciplinary perspectives on peer review at the AAC\&U Conference session. Jane Carr conducted an extensive and valuable literature review. Finally, our thanks to all participants in the sessions at 2012 IARSLCE and 2013 AAC\&U conferences for their insights and contributions.

\section{Author Note}

The authors are all founding members of the Working Group on Rethinking Peer Review.

\section{Correspondence}

Correspondence concerning this article should be addressed to: Sherril B. Gelmon, Hatfield School of Government, Portland State University, PO Box 751, Portland, OR 97207-0751; gelmons@pdx.edu

\section{References}

Albert Einstein College of Medicine, The Bronx Health Link and Community Campus Partnerships for Health. (2012). Community IRBs and Research Review Boards: Shaping the Future of Community-Engaged Research. Retrieved from http://depts.washington.edu/ccph/pdf_files/Shaping_the_Future_of_CEnR.pdf

Blanchard, L. W., Hanssmann, C., Strauss, R. P., Belliard, J. C., Krichbaum, K., Waters, E., \& Seifer, S. D. (2009). Models for faculty development: What does it take to be a communityengaged scholar? Metropolitan Universities Journal, 20(2), 47-65.

Burnham, J. C. (1990). The evolution of editorial peer review. Journal of the American Medical Association, 263(10), 1323-1329.

Calleson, D. C., Jordan, C., \& Seifer, S. D. (2005). Community-engaged scholarship: Is faculty work in communities a true academic enterprise? Academic Medicine, 80(4), 317-321.

Calleson, D., Kauper-Brown, J., \& Seifer, S. D. (2005). Community-engaged scholarship toolkit. Seattle: Community-Campus Partnerships for Health. Retrieved from http://www.communityengagedscholarship.info

Community-Campus Partnerships for Health (CCPH). (2005). Linking scholarship and communities: Report of the Commission on Community-Engaged Scholarship in the Health Professions. Seattle: Community-Campus Partnerships for Health.

Community-Campus Partnerships for Health (CCPH). (2006). Principles of good community-campus partnerships. Retrieved from http://depts.washington.edu/ccph/principles.html\#principles 
10 | International Journal of Research on Service-Learning and Community Engagement

Day, N. E. (2011). The silent majority: Manuscript rejection and its impact on scholars. Academy of Management Learning \& Education, 10(4), 704-718.

Freeman, E., Gust, S., \& Aloshen, D. (2009). Why faculty promotion and tenure matters to community partners. Metropolitan Universities Journal, 20(2), 87-103.

Gelmon, S. B, Jordan, C., \& Seifer, S. D. (2013). Community-engaged scholarship in the academy: An action agenda. Change: The Magazine of Higher Learning, 45(4), 58-66.

International Journal of Research on Service-Learning and Community Engagement. (2013). Focus and scope. Retrieved from http://journals.sfu.ca/iarslce/index.php/journal/about/editorialPolicies\#focusAndScope

Jordan, C. M., Gelmon, S., Ryan, K., \& Seifer, S. D. (2012). CES4Health.info: A web-based mechanism for disseminating peer-reviewed products of community-engaged scholarship: Reflections on year one. Journal of Higher Education Outreach and Engagement, 16(1), 47-61.

Jordan, C. M., Seifer, S. D., Sandmann, L., \& Gelmon, S. (2009). CES4Health: Development of a peer-review mechanism for disseminating innovative products of community-engaged scholarship. International Journal of Prevention Practice and Research 1(1), 21-28.

Jordan, C. M., Wong, K. A., \& Jungnickel, P. W. (2009). The community-engaged scholarship review, promotion, and tenure package: A guide for faculty and committee members. Metropolitan Universities Journal, 20(2), 66-86.

Kotchen, T. A., \& Spellecy, R. (2012). Peer review: A research priority. Paper commissioned by the Patient Centered Outcomes Research Institute. Retrieved from http://www.pcori.org/assets/PeerReview-A-Research-Priority2.pdf

Kronick, D. A. (1990). Peer review in $18^{\text {th }}$ century scientific journalism. Journal of the American Medical Association, 263(10), 1321-1322.

National Institutes of Health (NIH), Office of Extramural Research. Grants and funding: Peer review. Retrieved from http://grants.nih.gov/grants/peer_review_process.htm

Northcraft, G. B., \& Tenbrunsel, A. E. (2012). Publications, contributions and the social dilemma of scholarly productivity: A reaction to Aguinis, Debruin, Cunningham, Hall, Culpepper, and Gottfredson (2010). Academy of Management Learning \& Education, 11(2), 303-308.

Schieffer, D., Isaacs, D., \& Gyllenpalm, B. (2004). The world café: Part 1. World Business Academy, 18(8), 1-16.

Seifer, S. D., Hawkins, L., Daly, K., \& Fletcher, F. (2011). Recognizing and rewarding communityengaged scholarship: Implications for faculty development, tenure and promotion. Paper presented at CU Expo Conference, Kitchener, ON. Retrieved from http://cescholarship.ca

Wenger, L., Hawkins, L., \& Seifer, S. D. (2012). Community-engaged scholarship: Critical junctures in research, practice, and policy. Journal of Higher Education Outreach and Engagement, 16(1), 171-182. Retrieved from http://openjournals.libs.uga.edu/index.php/jheoe/index

Wineburg, S. (2013, September 6). Choosing real-world impact over impact factor. The Chronicle Review, p. B2. 